\title{
Iron Study is a Weak Indicator in Symptomatic C282Y/ H63D Compound Heterozygotes
}

Wael Toama ${ }^{1^{*}}$, Almaan El-Attrache ${ }^{1}$, Neel Patel $^{1}$ and Frederick T. Murphy ${ }^{2}$

${ }^{1}$ Conemaugh Memorial Medical Center, Johnstown, PA, USA

${ }^{2}$ Altoona Arthritis \& Osteoporosis Center, University of Pennsylvania, USA

"Corresponding author: Wael Toama, MD, Conemaugh Memorial Medical Center, Johnstown, Franklin, St. Johnstown, PA 15905, USA, Tel: 814-534-9408, Fax: 814-534-3290, E-mail: wael_tohma@yahoo.com

Rec date: March 25, 2015; Acc date: May 01, 2015; Pub date: May 15, 2015

Copyright: $\odot 2015$ Toama W, et al. This is an open-access article distributed under the terms of the Creative Commons Attribution License, which permits unrestricted use, distribution, and reproduction in any medium, provided the original author and source are credited.

\begin{abstract}
Hemochromatosis is a metabolic disease with protean manifestations including polyarthritis. It is often under diagnosed due to poor classification criteria, ambiguity in laboratory testing and the inability to obtain a histological diagnosis. The current DNA testing for hemochromatosis may not adequately identify patients at risk for indolent chronic migratory arthropathy secondary to this condition. In this case, we present a patient with compound heterozygotes of hemochromatosis laboratory testing, indolent chronic migratory polyarthritis, generalized weakness, depression and abnormal iron studies. Our subject presented to medical attention with a four-year history of indolent chronic migratory polyarthritis resulting in multiple orthopedic surgeries including right shoulder replacement and left ankle fusion. The patient's laboratory results including Complete Blood Count (CBC) and Comprehensive Metabolic Panel (CMP) showed mild elevated liver enzymes and transferrin saturation percentage. Iron studies demonstrated mild elevation in ferritin value, but returned to normal limits with oral steroid and NSAID treatments. A thorough serologic work-up for rheumatic, immunologic and infectious diseases were within normal limits. Physical examination revealed thickening and tenderness of the meta-carpophalangeal joints. The distribution of joint involvement prompted further testing for secondary causes of polyarthritis such as hemochromatosis. Genetic testing for hemochromatosis identified the C282Y and H63D alleles of the HFE gene.
\end{abstract}

The variable range of iron studies in patients with compound heterozygotes portends iron studies alone as a weak indicator of probability of the disease. Laboratory testing in classical hemochromatosis is typically associated with, elevated iron studies, elevated ferritin and transferrin saturation in addition to abnormal liver associated enzymes depending upon the duration and severity of the disease. This standard laboratory studies may not be sensitive enough to identify patients with hemochromatosis with or without associated polyarthritis early in their disease course.

Keywords: Iron; Heterozygotes; Hemochromatosis; Arthritis

\section{Introduction}

The most common mutations of the HFE gene involved in Hereditary Hemochromatosis $(\mathrm{HH})$ are $\mathrm{C} 282 \mathrm{Y}$ and H63D. The homozygosity of $\mathrm{C} 282 \mathrm{Y}$ is the most common mutation found in $85 \%$ to $100 \%$ of patients with the clinical phenotype [1,2]. However, heterozygosity for the $\mathrm{C} 282 \mathrm{Y} / \mathrm{H} 63 \mathrm{D}$ is defined in many screening studies without any clinical importance, which questions the positive productive value of genetic testing in asymptomatic individuals.

In general, the triad of Hemochromatosis diagnosis, which includes clinical symptoms, abnormal iron studies and confirmed genetic tests, has avoided many liver biopsies. The manifestations of Hemochromatosis include polyarthritis, heart failure, a broad spectrum of liver injuries from liver enzyme abnormalities to cirrhosis, pancreatic and pituitary hormons insufficiencies [Table 1]. The protean manifestations make iron studies a step before confirming genetic test. The tight link between clinical symptoms and iron studies, including ferritin and transferrin saturation, is very variable especially in the compound heterozygotes, which will delay the genetic test and the final diagnosis.

\section{Case Report}

A 47-year-old male presented with intermittent polyarthritis including wrists, low back, shoulders, hips, and knees with morning stiffness. His symptoms started gradually during the last 4 years have prompted orthopedic surgeries to include right shoulder replacement and left ankle fusion. He also has generalized weakness with depressed mood.

The patient has a history of exposure to arsenic and carbon monoxide via his occupation with losing two phalanges of the right middle finger. Family history was negative to rheumatic diseases and other notorious diseases.

The patient's laboratory results were all, except iron studies, unremarkable and included the following:

hemoglobin $15.6 \mathrm{~g} / \mathrm{dl}$, hematocrit 46.3\%, PLT $213 \mathrm{~K} / \mu \mathrm{L}$, WBC 7.7 $\mathrm{K} / \mu \mathrm{L}$, basic metabolic panel ,urinalysis, Lyme disease titers, ANA, rheumatoid factor, anti-CCP, RPR, HLA-B27, TSH,homocysteine, B12, and folic acid. His inflammatory markers, ESR and CRP, were elevated but returned to normal limits with oral steroid and NSAID treatments. 
Radiographic studies of pelvis and both knees within normal limits. However, X-rays of bilateral hands demonstrate the presence of the antecedent amputaion of the left 2nd distal phalanx, carpal and metacarpophalangeal (MCP) joints within normal limits, it is noted asymmetrical joint space narrowing in the distal and proximal interphalangeal (PIP) joints.

\begin{tabular}{|l|}
\hline Apathy, Lethargy, Weakness \\
\hline Arthralgias, Joint swelling, especially 2nd and 3rd metacarpophalangeal joints \\
\hline Hypogonadism: Loss of libido, Impotence, Amenorrhea, Testicular atrophy \\
\hline Abdominal pain, Hepatomegaly \\
\hline $\begin{array}{l}\text { 1.Skin manifestations of chronic liver disease: (e.g., spider nevi, palmar } \\
\text { erythema) }\end{array}$ \\
\hline 2. Increased pigmentation (bronze diabetes), rare late finding \\
\hline Cirrhosis: Ascites, Esophageal varices, Splenomegaly \\
\hline Cardiomyopathy, Dysrhythmias, congestive heart failure \\
\hline Diabetes mellitus \\
\hline Hypothyroidism \\
\hline Osteoporosis \\
\hline Weight loss \\
\hline
\end{tabular}

Table 1: Clinical symptoms and physical manifestations in patients with hereditary hemochromatosis $[4,8,9,17]$.

MRI of both knees demonstrate tendonitis and small erosion. Physical examination of the joints including shoulder, elbows, wrists, MCPs, PIPs, pelvis kness and ankles showes stiffnesss and thickening and tenderness in MCPs, without limitation of the range of motion, swelling, warmness or redness. Other physical examination was within normal limits.

During symptomatic arthritis episode, the patient's iron studies were elevated mildly: iron $146.8 \mu \mathrm{g} / \mathrm{dL}$ (normal 35.0 - 140.0), transferrin saturation (TS) $41.8 \%$ (normal $7.0-26.0 \%$ ), and serum ferritin (SF) $456 \mu \mathrm{g} / \mathrm{L}$ (normal 30-400 $\mu \mathrm{g} / \mathrm{L}$ ). High ferritin associated with high CRP 0.8 (normal 0-0.5) and normal ESR. Ferritin and CRP dropped to normal limits $382 \mu \mathrm{g} / \mathrm{L}$ and $0.1 \mathrm{mg} / \mathrm{dl}$ respectively after steroid treatment, his symptoms improved partially on steroid which continued at $10 \mathrm{mg}$. Notably, the patient's alkaline phosphatase had a mild but persistent elevation at $146 \mathrm{U} / \mathrm{L}$ (normal $34-129 \mathrm{U} / \mathrm{L}$ ), with normal liver transaminase AST $23 \mathrm{U} / \mathrm{L}$; ALT $21 \mathrm{U} / \mathrm{L}$. Genetic testing for hemochromatosis identified the $\mathrm{C} 282 \mathrm{Y}$ and H63D alleles of the HFE gene.

\section{Discussion}

The clinical presentation of hemochromatosis was associated in 85 to 90 percent of cases with homozygosity for the C282Y mutation of HFE gene which is known as classical hemochromatosis, but clinical hemochromatosis also presents in a small portion of cases with compound heterozygotes. Most persons who are positive for $\mathrm{C} 282 \mathrm{Y}$ homozygosity are asymptomatic and only 10 percent of those present clinically, $[3,4]$.

In Hemochromatosis and Iron-Overload Screening [HEIRS] study, the prevalence of $282 \mathrm{Y} / \mathrm{H} 63 \mathrm{D}$ compound heterozygosity was $2 \%$ [5].
The penetrance of the $\mathrm{C} 282 \mathrm{Y} / \mathrm{H} 63 \mathrm{D}$ heterozygous genotype is very variable and the occurrence of clinical iron overload disease is extremely rare [6].

The clinical presentation is related to iron overload in many organs such as skin, pituitary gland, pancreas, heart, liver and joints Table 1. Symptoms are nonspecific and typically absent in the early stages. If present, symptoms may include weakness, lethargy, arthralgias, and impotence [3-4,7-9]. The typical clinical manifestations of iron overload seen in homozygous $\mathrm{HH}$ appear to be quite uncommon in patients who are compound heterozygotes for $\mathrm{HH}[10,11]$ even in cases have serum transferrin saturation values that is compatible with homozygous $\mathrm{HH}[10]$.

It is unknown if iron deposits in target organs precede or parallel to the elevation in serum studies, or the possibility that joint damage in patients with HFE mutations is independent of iron (perhaps due to as-yet unidentified immunological effects of the HFE mutations) cannot be excluded [12]. Iron studies level is still good indicator of organ damage in homozygous $\mathrm{HH}$ for example, liver damage is expected when ferritin is higher than $1000 \mathrm{ng} / \mathrm{ml}$, but the situation will be different in case of arthropathy in compound heterozygotes where the damage can happen in mild elevation or normal range.

The iron overload is still the corner stone in the diagnosis, but elevation in serum iron studies could be delayed and does not reflect the damage degree of end organ. The clinical correlation with genetic test is required especially in unknown (as-yet unidentified immunological) etiology of arthropathy which is still the most presentation of compound heterozygotes of hemochromatosis.

In many articles, the diagnosis of hereditary hemochromatosis requires increased iron stores, with or without symptoms. C282Y homozygosity in the absence of elevated iron stores is not diagnostic for hereditary hemochromatosis. The genetic test is ordered to confirm the diagnosis in patient with clinical presentation and high iron studies. However this recommendation may be reconsidered, HFE mutation analysis should be performed in a case (such as our case) where arthropathy presented as atypical arthritis with mild or even normal upper limit of iron studies, further studies may be needed.

Negative iron studies are used to rule out the disease in children who have one parent with hereditary hemochromatosis if the other parent does not have it [11]. A normal serum ferritin level with transferring saturation less than $45 \%$ has a negative predictive value of 97\% for excluding iron overload [13]. Additionally, an elevated serum ferritin level is not diagnostic for hereditary hemochromatosis [7].

However, serum ferritin value is still the most important prognostic test in patients with homozygous hemochromatosis: a level less than $1,000 \mathrm{ng}$ per $\mathrm{mL}(2,247$ pmol per $\mathrm{L})$ predicts the absence of cirrhosis [14-17]. And avoid unnecessary liver biopsy used usually to determine the degree of fibrosis or cirrhosis.

Is there another indicator of hemochromatosis? Noninvasive specialized magnetic resonance imaging (MRI) techniques may be used to determine the degree of hepatic iron content or to diagnose nonclassical hemochromatosis in patients with $\mathrm{C} 282 \mathrm{Y}$ heterozygosity and severely elevated ferritin levels [3]. There is no data to use it in patients without elevated ferritin.

The frequency of phlebotomy is guided by serial measurements of serum ferritin levels and transferring saturation in hereditary hemochromatosis with a goal of 50 to $150 \mathrm{ng}$ per mL (112.35 to 337.05 
Citation: Toama W, El-Attrache A, Patel N, T. Murphy F (2015) Iron Study is a Weak Indicator in Symptomatic C282Y/ H63D Compound Heterozygotes . J Arthritis 4: 153. doi:10.4172/2167-7921.1000153

Page 3 of 3

pmolper L). In the light of absence of strict correlation between iron study and organs damage in C282Y/H63D heterozygous genotype with normal limit of ferritin, what will be the guider of phlebotomy if performs.

Facing of this challenge should be taken to try to prevent complications which sometimes even with treatment will not be reversible such as established cirrhosis or significantly arthropathy, testicular atrophy, or thyroid dysfunction [3].

All the offspring form this patient will be carrier and other family members are at increased risk. Even there is no official recommendation but genetic counseling and $\mathrm{HH}$ molecular testing are recommended for at risk family member.

\section{Conclusion}

In patients with atypical presentation of rheumatologic symptoms, hemochromatosis in all genetic types can be the underlying cause and genetic testing should be performed even with normal iron studies.

As demonstrated in this case report, standardized laboratory testing and treatment with phlebotomy may not be sensitive diagnostic or therapeutic interventions in patients with compound heterozygotes of hemochromatosis.

Additional clinical studies are warranted to further evaluate the predictive value of diagnostic and genetic testing in hemochromatosis. Furthermore, therapeutic options in addition to phlebotomy should be considered in patients with polyarthritis associated with Hemochromatosis.

\section{References}

1. Feder JN, Gnirke A, Thomas W, Tsuchihashi Z, Ruddy DA, et al. (1996) A novel MHC class I-like gene is mutated in patients with hereditary haemochromatosis. Nat Genet 13: 399-408.

2. Bomford A (2002) Genetics of haemochromatosis. Lancet 360 1673-1681.

3. Bacon BR, Adams PC, Kowdley KV, Powell LW, Tavill AS (2011) Diagnosis and management of hemochromatosis: 2011 practice guideline by the American Association for the Study of Liver Diseases. Hepatology 54: 328-343.
4. Iron Disorders Institute http://www.irondisorders.org/

5. Gurrin LC, Bertalli NA, Dalton GW, Osborne NJ, Constantine CC, et al. (2009) HFE C282Y/H63D compound heterozygotes are at low risk of hemochromatosis-related morbidity. Hepatology 50: 94-101.

6. Adams PC, Reboussin DM, Barton JC, McLaren CE, Eckfeldt JH, et al. (2005) Hemochromatosis and iron-overload screening in a racially diverse population. N Engl J Med 352: 1769-1778.

7. European Association For The Study Of The Liver1 (2010) EASL clinical practice guidelines for HFE hemochromatosis. J Hepatol 53: 3-22.

8. Valenti L, Varenna M, Fracanzani AL, Rossi V, Fargion S, et al. (2009) Association between iron overload and osteoporosis in patients with hereditary hemochromatosis. Osteoporos Int 20: 549-555.

9. Guggenbuhl P, Deugnier Y, Boisdet JF, Rolland Y, Perdriger A, et al. (2005) Bone mineral density in men with genetic hemochromatosis and HFE gene mutation. Osteoporos Int 16: 1809-1814.

10. Bulaj ZJ, Griffen LM, Jorde LB, Edwards CQ, Kushner JP (1996) Clinical and biochemical abnormalities in people heterozygous for hemochromatosis. N Engl J Med 335: 1799-1805.

11. Iron Disorders Institute. Hemochromatosis diagnosis algorithm: clinical evaluation \& management protocol. http://www.irondisorders.org/

12. de Almeida SF, Carvalho IF, Cardoso CS, Cordeiro JV, Azevedo JE, et al. (2005) HFE cross-talks with the MHC class I antigen presentation pathway. Blood 106: 971-977.

13. Bassett ML, Halliday JW, Ferris RA, Powell LW (1984) Diagnosis of hemochromatosis in young subjects: predictive accuracy of biochemical screening tests. Gastroenterology 87: 628-633.

14. Guyader D, Jacquelinet C, Moirand R, Turlin B, Mendler MH, et al. (1998) Noninvasive prediction of fibrosis in C282Y homozygous hemochromatosis. Gastroenterology 115: 929-936.

15. Bacon BR, Olynyk JK, Brunt EM, Britton RS, Wolff RK (1999) HFE genotype in patients with hemochromatosis and other liver diseases. Ann Intern Med 130: 953-962.

16. Morrison ED, Brandhagen DJ, Phatak PD, Barton JC, Krawitt EL, et al. (2003) Serum ferritin level predicts advanced hepatic fibrosis among U.S. patients with phenotypic hemochromatosis. Ann Intern Med 138: 627-633.

17. Beaton M, Guyader D, Deugnier Y, Moirand R, Chakrabarti S, et al. (2002) Noninvasive prediction of cirrhosis in C282Y-linked hemochromatosis. Hepatology 36: 673-678. 